Thorax (1951), 6, 403.

\title{
THORACIC CHORDOMA
}

\author{
BY \\ G. G. CROWE AND P. B. LL. MULDOON \\ From City General Hospital, Stoke-on-Trent
}

(RECEIVED FOR PUBLICATION AUGUST 22, 1951)

\begin{abstract}
Remnants of the notochord sometimes become activated into tumour formation ; Ribbert (1895) established the origin of such tumours, and called them chordomata. They can arise at any point along the length of the original notochord, and Coenen (1925) first classified them according to their site of origin into cranial, vertebral, and caudal or sacro-coccygeal. Mabrey (1935) in a comprehensive review of all cases reported in the literature found that 47 were cranial, 14 vertebral, and 87 caudal in origin. Only two of the 14 vertebral cases were thoracic, and for this reason the present case is worthy of note. The patient presented with a spherical tumour in the upper posterior mediastinum, which was removed after thoracotomy, and is the first case reported in the literature of a thoracic chordoma removed by operation.
\end{abstract}

\section{CASE REPORT}

G. G. C., aged 30, a flue-man at a gas works, was admitted to hospital on December 29, 1950. He had been fit until September, 1950, when he stated that he had had pneumonia, which was treated with sulphonamides. His doctor stated that the pneumonia had cleared up, but since that time he had had persistent cough and purulent sputum (about $4 \mathrm{oz}$. daily), associated with loss of weight ( 2 st.), anaemia, malaise, and sweating. He gave a history of having had pneumonia in childhood, and he had served for five years in the Forces during the war without ill-effect, except for a gunshot wound in the right arm.

On examination he was seen to be pale, thin, and had obviously lost weight. His general condition was poor, but he had no fever. Examination of the chest revealed an impaired percussion note and râles at the right base, and distant bronchial breath sounds in the right upper zone. There was no specific abnormality in the cardiovascular system or abdomen. The pulse was 100 and the blood pressure $120 / 80$. His weight was 6 st. $10 \mathrm{lb}$. Sputum showed numerous pus cells and a mixture of organisms. No tubercle bacilli were found.

The haemoglobin was $74 \%$. The red blood cell count was 4.2 millions per c.mm., and the colour index 0.89 . The white blood cell count was 10,100 per c.mm. (polymorphs $75 \%$, lymphocytes $25 \%$, platelets adequate), and there was moderate anisocytosis, hypochromia, and slight polychromasia.

A radiograph of the chest (Fig. 1) showed a rounded mass in the posterior superior mediastinum, situated centrally. Along the right border of this mass were calcified plaques. There was some opacity at the base of the right lung suggesting pneumonitis. Fluroscopy showed that the mass was not pulsatile. A barium swallow showed the oesophagus to be displaced forward and to the left (Fig. 2). There was no lesion of the oesophagus. 


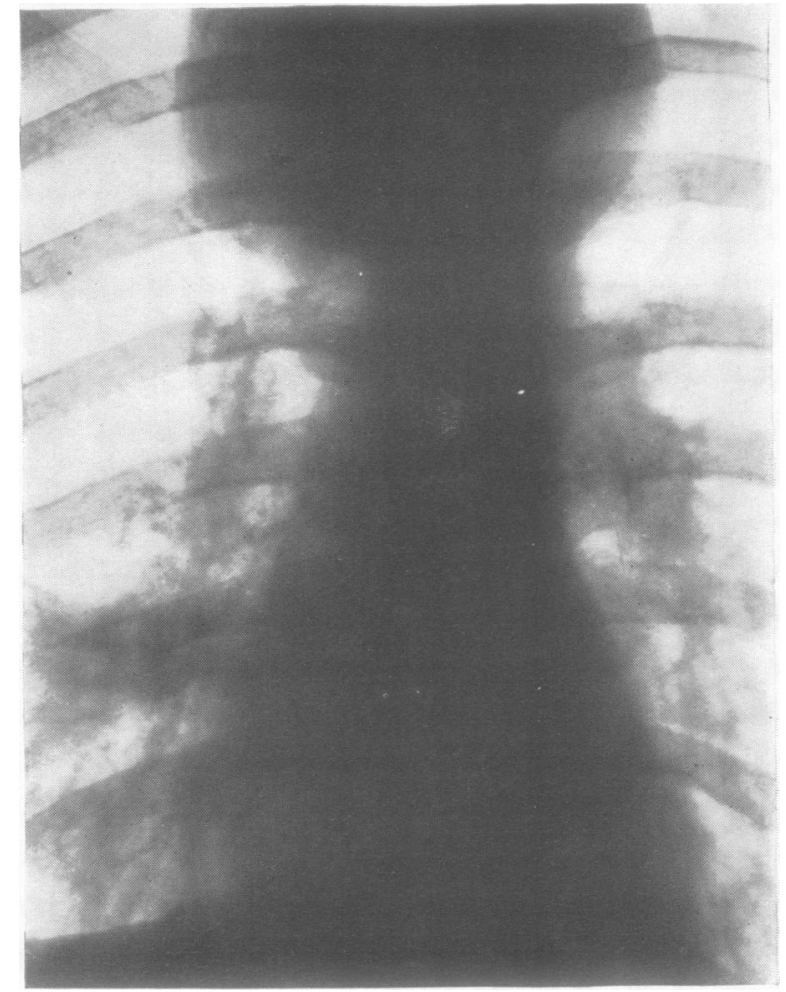

FIG. 1.

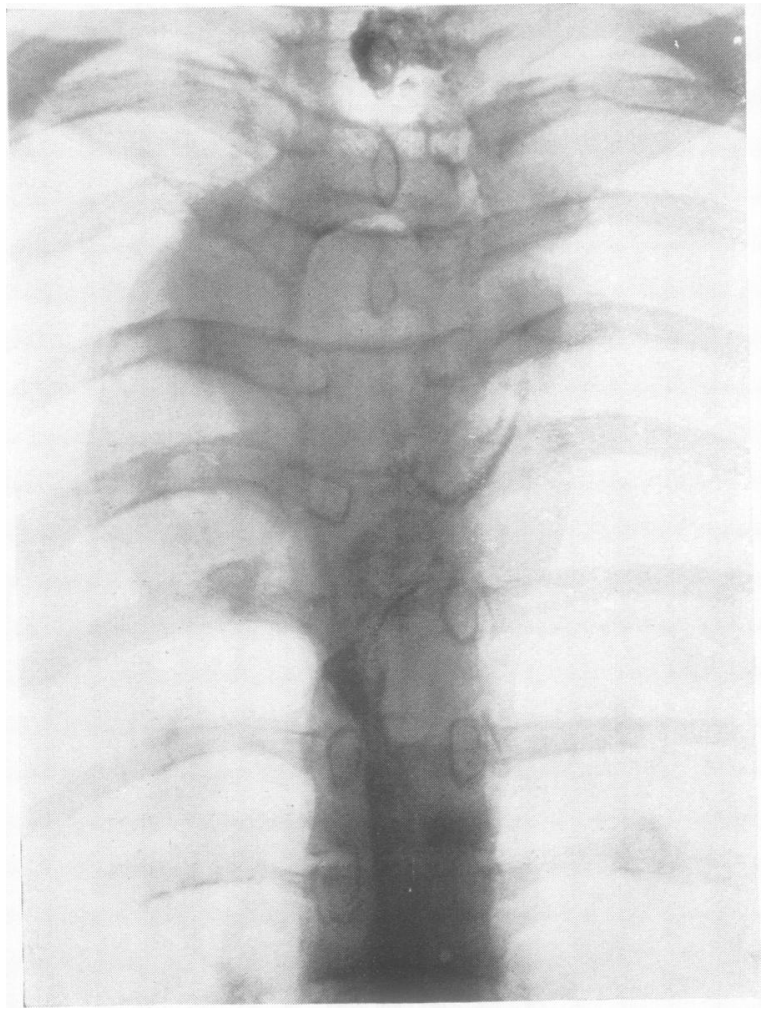

FIG. 1.-Postero-anterior radiograph showing a rounded mass in the upper posterior mediastinum.

FIG. 2.-Radiograph after a barium swallow, showing the oesophagus displaced to the left.

FIG. 2. 
It was felt that the patient had a chondroma of the posterior mediastinum arising from the posterior end of one of the upper four ribs compressing the right main bronchus, and thoracotomy was advised.

He was given a course of penicillin to control the lung infection, and two infected teeth were removed.

On January 15,1951 , the patient began to complain of dysphagia. On January 23, thoracotomy was performed through the bed of the sixth right rib. The upper lobe of the right lung was adherent to a large spherical mass in the posterior mediastinum. The mass was compressing the trachea and the oesophagus from behind, and the anaesthetist had so much difficulty in passing an endotracheal tube that the patient suffered anoxia during intubation. The mass was roughly spherical and about $20 \mathrm{~cm}$. in diameter. It was adherent to the spinal coiumn and had begun to erode the third and fourth thoracic vertebral bodies. It was well encapsulated, and was found to contain soft, yellow, necrotic material. It was removed piecemeal as completely as possible. The wound was closed in layers and a drain was left in through the ninth right intercostal space. A blood transfusion of 1.2 litres was given during the operation and $600 \mathrm{ml}$. later.

The post-operative course was stormy. There was copious bronchial secretion which had to be aspirated, and there was considerable bleeding from the drainage tube. About six hours after the operation it was noticed that he had a left-sided hemiparesis of the upper motor neurone type. This was considered to be due to cerebral damage brought about by the prolonged anoxia during operation. His condition gradually improved. He brought up some blood-stained sputum for four days after operation and about $3 \mathrm{oz}$. of blood-stained fluid were aspirated from the chest on January 27, 1951. During this time he was given a course of procaine penicillin, 150,000 units b.d. His temperature settled in five days and the paresis cleared rapidly. He was allowed up a week after operation and was discharged home on February 28, 1951. Subsequently, he had a course of deep $x$-ray therapy and returned to work in April, 1951.

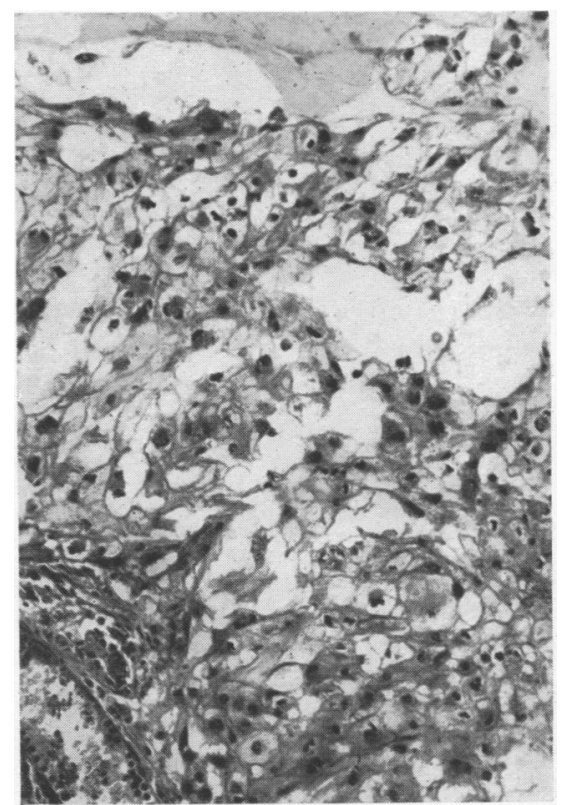

FIG. 3.-Photomicrograph of a section of the chordoma, showing large polyhedral cells with cytoplasmic vacuoles. (Low power, $H$. and $E$.)

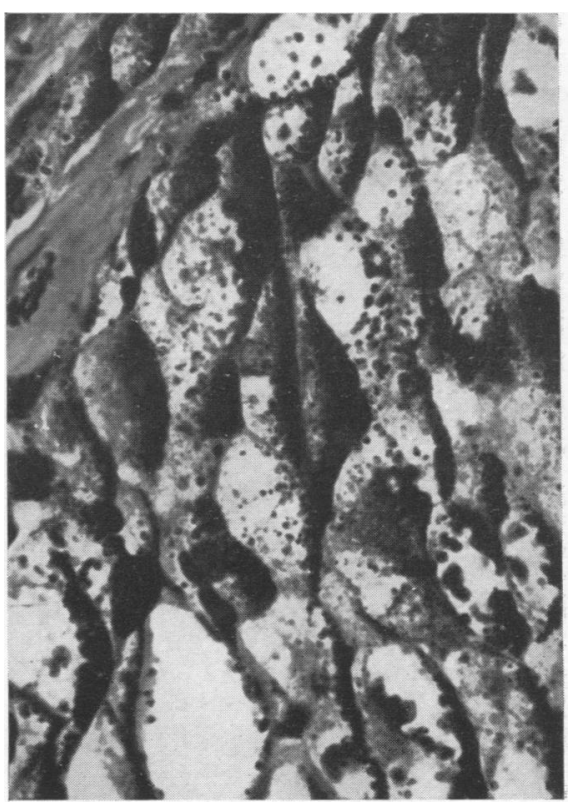

FIG. 4.-Photomicrograph of section of chordoma treated by the periodicacid-Schiff technique to demonstrate glycogen. (High power.) 
When he was seen at a routine follow-up in May, 1951, he felt and looked well, and had a good exercise tolerance.

Histological Report.-The specimen consisted of two fragments of soft, rather friable and gelatinous tissue, each piece measuring approximately $5 \times 2 \times 2 \mathrm{~cm}$.

Microscopic examination (Fig. 3) shows a vascular tumour which is made up of relatively large, fairly uniform polyhedral cells. The nuclei are oval with a vesicular pattern, except where they are displaced to the periphery of the cell by large cytoplasmic vacuoles. These cells are arranged in roughly spherical clumps by delicate trabeculae of vascular connective tissue and, in places, by a hyaline matrix. Glycogen can be demonstrated in the tumour cells by the periodic-acid-Schiff technique, controlled by diastasetreated preparations (Fig. 4). The histological appearance is that of a chordoma (Fig. 2).

\section{Discussion}

The differential diagnosis of such cases is of tumours arising in the posterior mediastinum ; encysted effusion, spinal caries, aneurysm of the aorta, tuberculoma, neurogenic tumours, chondroma, chondrosarcoma, fibroma, osteoma, meningocele, hydatid cyst, and achalasia of the cardia. There are no specific features beyond the effects of pressure. Most vertebral tumours reported have had radiological evidence of bony destruction, and involvement of the spinal cord by local infiltration causing nervous changes. The tumours are almost always attached to the vertebrae (Hansson, 1941 ; Faust, Gilmore, and Mudgett, 1944). The present case showed signs of bronchial and oesophageal pressure only, and, although the tumour was found to be attached to the third and fourth thoracic vertebrae, no radiological abnormality of these bones was found.

It seems that thoracic chordomata have a greater tendency to grow forwards than other vertebral chordomata. They occur at any age, but are commonest in the cancer period, and are twice as frequent in males as in females. There is frequently a history of trauma (Mabrey, 1935). The nucleus pulposus is a notochord remnant, and material from it might conceivably undergo malignant change. The largest tumour reported was $20 \times 30 \mathrm{~cm}$. (Richards and King, 1940). It was soft and jelly-like, grey or pink, well encapsulated, with gross nodularity in some places. The less mucinous and the more opaque the tumour is, the greater is the malignancy. When incised, the tumour may be filled with a jelly-like mass, or, as in the present case, with cheesy necrotic material.

Treatment is by surgical excision followed by deep $x$-ray therapy (Mabrey, 1935). Partial excision is justified to relieve pressure. Our patient has been completely relieved of his symptoms, although it was not possible to remove all of the tumour. Chordoma has a tendency to recur and metastases are not uncommon. In Mabrey's series the operative mortality for all cases of chordoma (cranial, vertebral, and caudal) was $18.8 \%$, and the average length of life after onset was 18 months.

\section{SUMMARY}

Chordomata are tumours arising in remnants of the foetal notochord. They are most common in the cranial and caudal regions, and uncommon in association with vertebrae. A case of thoracic chordoma, presenting as a mediastinal tumour, is described. The diagnosis and treatment are discussed. 
We wish to thank Drs. C. Giles, A. J. McCall, and E. M. Stirk for their help with the histology and microphotography.

\section{REFERENCES}

Coenen, H. (1925). Beitr. klin. Chir., 133, 1.

Faust, D. B., Gilmore, H. R., and Mudgett, C. S. (1944). Ann. intern. Med., 21, $6 \% 8$.

Hansson, C. J. (1941). Acta radiol., Stockh., 22, 598.

Mabrey, R. E. (1935). Amer. J. Cancer, 25, 501.

Ribbert (1895). Verh. Kongr. inn. Med., 13, 455.

Richards, V., and King, D. (1940). Surgery, 8, 409. 